EHJ Quality Improvement

\title{
Valvular Heart Disease in the Community The Unknown Knowns in Electronic Health Record Coding
}

Cian Mangan, MBBS ${ }^{\mathrm{a}}$; Filip Zemrak, MD, PhD ${ }^{\mathrm{a}, \mathrm{c}}$; Amitava Banerjee, MD, PhD ${ }^{\mathrm{a}, \mathrm{b}}$; Sanjeev Bhattacharyya, MD, PhD ${ }^{\text {a, c }}$; Thomas A Treibel, MD, PhD ${ }^{\text {a, b}}$; Guy Lloyd, $\mathrm{MD}^{\text {a, b, c }}$.

\author{
Affiliations: \\ a Barts Heart Centre, St Bartholomew’s Hospital, London, UK. \\ ${ }^{\mathrm{b}}$ Institute of Cardiovascular Science, University College London, London, UK. \\ ${ }^{\mathrm{c}}$ Queen Mary University, London, UK.
}

Word count: 969 / 1000 words

Correspondence Address:

Dr Guy Lloyd

Barts Heart Centre

St Bartholomew's Hospital

2nd Floor, King George V Block

London EC1A 7BE, United Kingdom

Tel: +44 2037658611

guy.1loyd1@nhs.net 
Valvular heart disease (VHD) is common and has major consequences for individuals, populations and health systems. ${ }^{1,2}$ Most of the burden and unmet need is in the community, where VHD is detected upon screening in $50 \%$ of adults aged $\geq 65$, but only known in half. ${ }^{1}$ Despite high prevalence, no community screening schemes for VHD exist, and late presentation with symptoms results in significant morbidity and mortality. ${ }^{3}$ Most clinical and research studies are hospital-based and probably not representative of the community. Community-based studies are needed to determine trajectory, best screening methodology and optimised timing of surgery. With increasing penetrance of electronic health records (EHRs) in the UK and many other countries, routine health care data could be used to achieve this: Linked EHRs have been used to develop validated disease phenotypes for many cardiovascular diseases. We set out to understand the quality of EHR coding for VHD in primary/secondary care in order to inform EHR phenotyping and future use of EHRs in clinical and research practice.

We conducted a retrospective study of VHD coding in primary care for patients diagnosed with significant VHD in a large tertiary referral centre (Barts Health). Barts Health provides regional echocardiography services to 4 locality-based hospitals in East London/UK (Figure 1), and therefore, has a comprehensive regional overview of VHD diagnoses. The implementation of an EHR sharing system (East London Patient Record [ELPR]) allowed comparison across tertiary and primary care coding. In a first step (Borough-Level), we took a random sample of patients from two London Boroughs with known VHD at tertiary level and looked at concordant coding in primary care. In a second step (Clinic-Level), we assessed the coding in a single large primary care practice $(14,949$ patients; 10 primary care doctors). Primary care records were searched for adult patients with at least one VHD diagnosis code. In a reciprocal approach, the tertiary centre 
database was searched to identify echocardiograms performed for this primary care practice. Original echocardiogram reports were then compared with practice coding to assess concordance of echocardiographic findings and primary care coding. Significant VHD was defined as echocardiographic evidence of valvular stenosis or regurgitation of at least moderate severity or previous valve repair/replacement. "Incorrect coding" was defined as: uncoded VHD, uncoded valve repair/ replacement, coding of incorrect valve or the code "abnormal echocardiogram".

At Borough-Level, health authority data showed low percentage of patients over 65 as would be expected for Inner City populations with Waltham Forrest accounting for 30,364 (9.8\%) and Tower Hamlets for 17,983 (5.5\% [lowest in the UK]). ${ }^{4}$ Of a random sample of 212 patients with a known diagnosis of significant VHD, we excluded $62(29 \%)$ as they were either deceased (17\%) or had opted out of ELPR (12\%). Of the remaining 150 cases, 79 (53\%) tertiary centre echocardiogram reports were correctly coded in primary care for a diagnosis of significant VHD; 27 (18\%) were coded incorrectly and $44(29 \%)$ not coded at all.

At Primary Care Clinic-Level, case record review of 14,949 registered patients revealed only 89 (0.6\%) patients with a code for VHD and 42 of 1,046 (4\%) of those aged >65 years. Search and review of hospital echocardiogram reports for these 89 patients revealed that only 35 (39\%) had a correct code matching the clinical or echocardiogram diagnosis; 17 (19\%) were coded incorrectly; in 37 patients (42\%) there was no corroborative echocardiogram report available at the tertiary centre. Conversely, the tertiary centre had records of 73 patients registered at this practice with a significant VHD diagnosis, with only 28 (36\%) coded at the practice, meaning 45 (64\%) were not coded/known in primary care. 
Our studies investigating coding for VHD reveals major discrepancies between hospital diagnosis and local primary care EHRs, both at a sample primary care practice and in a random sample of patients from two East London Boroughs. Nearly two thirds of diagnoses of significant VHD from tertiary care were either not appropriately coded/unknown to primary care. Considering that $50 \%$ of patients with significant VHD in the community were undiagnosed, up to $80 \%$ of patients with significant VHD may be unknown/uncoded in primary care. Our work also highlights that previous community data may not be translatable to a younger, more deprived, multi-ethnic Inner City populations. ${ }^{1,2}$

Our work highlights the need for better linkage of EHRs across primary and secondary care, as well as improved communication and coding across primary and secondary care. A recent panEuropean data showed that simple, low-cost, facilitated data relay for patients with VHD has been shown to reduce treatment delay. ${ }^{5}$ Furthermore there is a need for better linkage of EHR across primary and secondary care. Ultimately, we have to echo Nkomo's and OxValve's call to address the large unmet need for VHD screening in community. ${ }^{1,2}$

Conflict of Interest: GL received research grants from Medtronic; research grants, personal fees and non-financial support from Edwards Lifesciences; personal fees and non-financial support from General Electrics; and personal fees from Philips; all outside the submitted work. 


\section{FIGURES:}

Figure 1: Geographical location of the London boroughs of Tower Hamlet (\#2) and Waltham Forrest (\#5).

\section{REFERENCES:}

1. d'Arcy JL, Coffey S, Loudon MA, Kennedy A, Pearson-Stuttard J, Birks J, et al. Large-scale community echocardiographic screening reveals a major burden of undiagnosed valvular heart disease in older people: the OxVALVE Population Cohort Study. Eur Heart J 2016;37(47):3515-3522.

2. Nkomo VT, Gardin JM, Skelton TN, Gottdiener JS, Scott CG, Enriquez-Sarano M. Burden of valvular heart diseases: a population-based study. Lancet 2006;368(9540):1005-11.

3. Wald DS, Williams S, Bangash F, Bestwick JP. Watchful Waiting in Aortic Stenosis:

The Problem of Acute Decompensation. Am J Med 2018;131(2):173-177.

4. https://fingertips.phe.org.uk/profile/generalpractice/data\#page/8/gid/2000005/pat/46/par/E39000018/ati/152/are/E38000192

5. Steeds RP, Lutz M, Thambyrajah J, Serra A, Schulz E, Maly J, et al. Facilitated Data Relay and Effects on Treatment of Severe Aortic Stenosis in Europe. J Am Heart Assoc 2019;8(19):e013160. 